\title{
Present but not prevalent: identifying the organizational correlates of researcher-practitioner partnerships in U.S. Law Enforcement
}

\author{
Jeff Rojek ${ }^{a}$, John A. Shjarback ${ }^{b}$, John Andrew Hansen ${ }^{c}$ and Geoffrey P. Alpert ${ }^{d}$

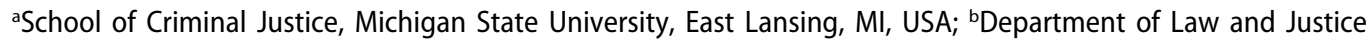 \\ Studies, Rowan University, Glassboro, NJ, USA; 'Department of Criminal Justice, Western Carolina University, \\ Cullowhee, NC, USA; dDepartment of Criminology and Criminal Justice, University of South Carolina/Griffith \\ University
}

\begin{abstract}
Federal funding streams, the International Association of Chiefs of Police, and policing executives and scholars alike have advocated for more researcher-practitioner partnerships in American law enforcement. While a few studies have explored the growth and prevalence of research partnerships in policing, less attention has been placed on the organizational correlates of such collaborative relationships. Using a nationally representative sample of US law enforcement agencies, the current study investigated participation in what we term 'rigorous partnerships' - more formal, long-term relationships between researchers and practitioners with increased opportunity for interactive knowledge exchange. Policy implications and directions for future research are discussed, with a specific focus on the barriers and impediments that both parties face for successful collaborative efforts and research translation.
\end{abstract}

\section{KEYWORDS}

Police; partnerships;

translational criminology

There has been a concerted effort over the last few decades to foster more researcher-practitioner partnerships in American law enforcement. For example, a number of federally funded programs have provided grant money to agencies with the requirement/stipulation that they partner with members of the research community. These programs include CeaseFire, Drug Market Analysis Program (DMAP), Locally Initiated Researcher Partnerships (LIRP), Strategic Approach to Community Safety Initiative (SACSI), Project Safe Neighborhoods (PSN), and, most recently, the Bureau of Justice Assistance's Smart Policing Initiative (SPI). The International Association of Chiefs of Police (IACP) is perhaps the most prominent advocate for such partnerships. In a 2004 report, IACP asserted partnerships were 'critical to discovering and implementing best policing practices' (p. 3) - arguing that developing researcher-practitioner partnerships should be a primary goal for every law enforcement agency in the country. Additionally, the National Institute of Justice (2017), in its Strategic Research Plan through 2022, has pledged continued funding to promote research to examine policeresearcher partnerships and their impact on public safety.

Yet, few studies have explored the growth and prevalence of research partnerships in policing. International Association of Chiefs of Police (2011) conducted a survey of its members in late 2009: finding that $45 \%$ of the 731 responding departments had collaborated in the past or were currently collaborating with college/university researchers. More recently, Alpert, Rojek, and Hansen (2013) conducted a nationally representative survey with $32 \%$ of responding agencies reporting involvement in partnerships. And while much more has been learned about the 
prevalence of research partnerships in policing, little empirical work has examined the predictors of those partnerships. As such, the field lacks an understanding of which factors contribute to their successes or failures and the type of agencies that are willing to engage in them.

In an effort toward this goal and expanding on prior research, we examined the organizational correlates of researcher-practitioner partnerships in U.S. law enforcement. ${ }^{1}$ Using a nationally representative sample of 871 agencies of all sizes (see Alpert et al., 2013; Rojek, Smith, \& Alpert, 2012a), the current study employed multivariate analysis to investigate participation in what we term 'rigorous partnerships'. A particular focus is placed agencies' orientation/openness to research and as well as the specific sources of those research outlets.

\section{Literature review}

\section{Shared governance, research utilization, and knowledge translation}

Problems confronting public institutions have become more complex in recent years. A number of fields and disciplines (e.g., public administration, medicine) have recognized that one potential solution to address these concerns lies in the adoption of a 'governance framework' based on a process of shared responsibility among government institutions and stakeholders (i.e., 'shared governance'). The primary mechanism government institutions have used to foster such shared governance has been the formation of partnerships with other government agencies/entities, community members and organizations, private organizations, and academic institutions (Vigoda, 2002). The rationale behind, as well as the underlying goal, of these partnerships is to combine the resources, skills, and knowledge of the actors in a way that allows them to achieve better results in managing problems more effectively and efficiently than could be accomplished either individually or by government agencies alone (Lasker, Weiss, \& Miller, 2001). A wide variety of partnerships in law enforcement exist, including community policing and multijurisdictional task forces. However, it is the formation of police practitioner-researcher partnerships, because of their potential benefits, that are deserving of more scholarly attention.

Collaborations between law enforcement and the research community hinge on the interrelated concepts of 'research utilization' and 'knowledge translation' (see Green, Ottoson, Garcia, \& Haitt, 2009; Henry \& MacKenzie, 2012; Lang, Wyer, \& Eskin, 2007). 'Translational criminology', in fact, fits neatly within this broader framework. While both sides of the practitioner-researcher partnership arguably benefit from said participation, the public policy consideration has largely focused on how the researcher can improve the law enforcement agency and/or its practices. The research partner, ideally, adds a degree of empirical knowledge, various methodologies, and analytical skills that can improve an agency's ability to identify problems and formulate effective responses. It is assumed that such relationships will lead practitioners/agencies to integrate findings from established and accepted scientific methodology into efforts to evaluate police responses and understand social problems (i.e., bringing research to practice). In turn, these results will, theoretically, make police agencies more effective in serving their respective communities (Braga \& Hinkle, 2010; International Association of Chiefs of Police, 2004). As such, police practitioner-researcher partnerships represent an interpersonal form of research utilization by law enforcement agencies.

It is important to note that not all partnerships are created equally, and they vary in the degree to which they create opportunities for research utilization and knowledge translation. The most effective collaborations aim to foster more interactive, two-way exchanges of information between police practitioners and researchers. From a research utilization/knowledge translation standpoint, these types of interactive exchanges are, without a doubt, more desirable than passive forms, such as researchers publishing results from studies with the expectation that practitioners will locate and incorporate this knowledge on their own. We frame involvement in partnerships as a form of research utilization/knowledge translation. 


\section{History, advocacy, and the prevalence of researcher-practitioner partnerships ${ }^{2}$}

Federal funding has provided perhaps the biggest impetus for the creation and growth of such partnerships. According to Sherman (2004), the NIJ funded Drug Market Analysis Program (DMAP), with the goal of evaluating police efforts addressing illegal drug markets, was one of the first streams of grant initiatives requiring the partnership of practitioners with researchers. DMAP, however, ended in the mid-1990s. The next NIJ funding stream - the Locally Initiated Research Partnerships (LIRP) in policing program - occurred between 1995-1996; 41 police practitioner-researcher partnerships were granted money to engage in problem-oriented policing/SARA-type (i.e., scanning, analysis, response/intervention, assessment) projects (McEwen, 2003). Aside from LIRP, NIJ also funded Operation CeaseFire - a collaboration between the Boston Police Department and researchers from Harvard University's John F. Kennedy School of Government (see Braga, Kennedy, Waring, \& Piehl, 2001). Because of its success in reducing youth violence, NIJ funded replication efforts (with collaborative partnerships between law enforcement and researchers) in 10 U.S. cities under the Strategic Approach to Community Safety Initiative (SACSI) (Roehl et al., 2006). Similar efforts were followed by the Project Safe Neighborhoods (PSN) program (McGarrell et al., 2009) and, most recently, the Bureau of Justice Assistance's Smart Policing Initiative. In fact, Rojek and colleagues (2012a: 252) found that the number one reason why agencies reported not participating in partnerships was 'not having the funding or resources.'

IACP has been at the forefront of advocacy for partnerships for some time now. In 2004, they took assertive effort in creating a link between law enforcement practitioners and the research community through the formation of a Research Advisory Committee. The committee is comprised of both researchers and law enforcement leaders, and its mission is to 'help guide the IACP and its partners in identifying and conducting law enforcement policy research on the most important issues facing police executives' (Wellford, Serpas, \& Firman, 2007, p. 1). The committee has made promoting the development of police-researcher partnerships a priority. The National Institute of Justice (2017) also recently reported that it would continue to prioritize research on and the development of practitioner-researcher partnerships in its Strategic Research Plan for 2017-2022. In addition to organizations, a number of influential police leaders have called for the increase in partnerships. William Bratton (2006), then chief of the Los Angeles Police Department, delivering the keynote speech at the 2006 National Institute of Justice conference stated, 'I embrace and encourage the need for research, because I am a change agent, who constantly needs timely accurate information to help shape my initiatives and understand my challenges' (p. 1). Similar insight and messages can be found by Darrel Stephens (2010) and Jim Bueermann (2012).

Despite the federal funding over the past few decades, particularly from the National Institute of Justice, and the encouragement from prominent law enforcement organizations (e.g., IACP) and executives (e.g., William Bratton), little is known about the development and prevalence of researcher-practitioner partnerships among U.S. law enforcement. Most of the research that has been done is limited to case studies. One of the few exceptions was a review conducted by McEwen (2003); however, it only focused on the 41 practitioner-researcher partnerships funded through the LIRP policing program. Additionally, there have been two special issues dedicated to the topic in Police Practice and Research (Rojek, Alpert, \& Smith, 2012b; Stephens, 2010) and another in Policing: A Journal of Policy and Practice in 2010. This body of literature has discussed the benefits of partnerships, particularly for the police, and it has identified a number of interrelated factors that influence their development: trust, the involvement of the right individuals, communication, and the permanence of personnel.

International Association of Chiefs of Police (2011) conducted a survey of its 731 members in 2009, which explored their perceptions of research utilization and participation in partnerships. It represented an important first effort in measuring the prevalence of researcher-practitioner 
partnership; however, it was only conducted on a convenience sample of association agencies. While the majority of police organizations reported that they either 'often' or 'always' have an interest in learning about new research relevant to law enforcement and the justice system, their answers did not define the degree to which they use research to inform agency decisions/ operations, or even what constitutes the term 'research'. For example, $30 \%$ of responding agencies reported that research 'often' or 'always' influence their decisions, and another $61 \%$ of agencies reported that research 'occasionally' influences their decisions (International Association of Chiefs of Police, 2011). When asked about the specific sources of research that they rely on, more than $90 \%$ of agencies reported 'professional law enforcement associations' and more than $70 \%$ reported 'conferences and training courses.' On the other hand, approximately $40 \%$ mentioned 'academic or technical journals' and 34\% referenced 'universities and colleges' (International Association of Chiefs of Police, 2011). Some of the respondents, in fact, raised concerns in their survey responses about the 'relevance of academic or university-driven law enforcement research to the practical issues they face' (International Association of Chiefs of Police, 2011, p. 6).

In regard to the prevalence of police partnerships, $45 \%$ of the IACP member agencies reported that they had either collaborated with college/university researchers in the past or were currently collaborating with those researchers. Interestingly, proximity to a college/university did not seem to be a factor in contributing to research partnerships: as $60 \%$ of agencies who reported there was a college or university within 30 miles also reported having no experience in these collaborations. Knowledge of a local college or university's research capacity, however, did appear to influence participation, as $64 \%$ of those respondents who knew about the local research capacity had participated in collaborations. Conversely, $70 \%$ of agencies that were not aware of this local research capacity had never collaborated with a college or university researcher. The education level of the organization's chief executive also appeared to be a factor (International Association of Chiefs of Police, 2011). Police leaders with graduate degrees were more likely to have an interest in using research and their agencies were likely to have collaborated with a college/university researcher, followed by leaders with bachelor's or associate's degrees; chiefs with only high school diplomas reported the lowest rates on both measures - interest in research and history of collaboration.

Alpert and colleagues performed, arguably, the most rigorous evaluation of the prevalence of police practitioner-researcher partnerships to date. Using a nationally representative, stratified random sample, they uncovered a number of noteworthy findings regarding prevalence and distribution across agency size. Nearly one-third (32\%) of departments in the sample indicated that they had engaged in a partnership with researchers within the past five years (Alpert et al., 2013; Rojek, Smith et al., 2012a) - a figure lower than the International Association of Chiefs of Police (2011) count but more generalizable and broader than the sample of IACP members. In addition, the likelihood of involvement in a research partnership was largely associated with agency size. Nearly half (48\%) of departments in the sample with 100 or more sworn officers had engaged in a partnership compared to $25 \%$ of agencies with $50-99$ officers, $22 \%$ of agencies with 25-49 officers, $10 \%$ of agencies with 10-24 officers, and just $7 \%$ of departments with less than 10 officers (Rojek, Smith et al., 2012a).

\section{Current study}

Prior research on the topic has provided initial insight into the history, growth, and prevalence of practitioner-researcher collaboration in U.S. policing. Although these partnerships are certainly present and have likely increased in recent years, they are by no means prevalent - especially for smaller sized agencies. In addition to size, the education level of chief executives may also be related to the likelihood of participation while proximity to a college/university researcher might be inconsequential. Aside from these factors, which have largely been examined at the descriptive level, little empirical work has investigated other correlates, particularly organizational features, of willingness to 
engage in research partnerships. Given the framing of partnerships within the broader interest in research utilization/knowledge translation, we explored the potential link between orientation/openness to research and engagement in high-quality partnerships (i.e., where more opportunity for interactive knowledge exchange can take place). Moreover, due to the fact that there is reported variation in the sources of research findings (e.g., academic vs. professional journals; see International Association of Chiefs of Police, 2011), we examined the specific outlets where agencies are receiving knowledge (if at all) and whether it impacts participation in research collaborations. Because past studies have found that size matters, we paid particular attention to large agencies.

\section{Methods}

\section{Data and sample}

This study used data from a National Institute of Justice (NIJ) funded project on police partnerships as well as supplemental measures from the 2007 Law Enforcement Management and Administrative Statistics (LEMAS) survey. More specifically, it employed a national survey of a stratified random sample of 2,015 municipal, county, and state law enforcement agencies, which was drawn from the 2009 National Directory of Law Enforcement Agencies (NDLEA) database. The 2009 NDLEA database provides information on 15,759 state and local law enforcement organizations, including the name of the current chief executive and the agency address. In addition, it provides information on the type of agency (city/county police department; county sheriff; state police/highway patrol), population of the jurisdiction (under 10,000; 10,000-49,999; $50,000-99,999 ; 100,000-499,999 ; 500,000-999,999 ; 1,000,000+)$, and region of the country where the agency is located (northeast; Midwest; south; west) - all characteristics that were used for the stratified sampling criteria. All state law enforcement agencies $(n=50)$ and large municipal and county agencies serving populations of 100,000 or more $(n=827)$ were oversampled; the remaining sampling frame was randomly selected from agencies with jurisdictional populations of less than 100,000 and divided across the above population, region, and agency type categories.

Surveys were addressed to the chief executive of each agency and mailed between March and July 2010. Data collection included an initial survey mailing with two follow-up mailing reminders. A total of 871 agencies returned completed surveys, representing a $43 \%$ response rate. Four hundred and thirty-three (50\%) of those were city/county police departments, 404 (46\%) were county sheriffs, and $34(4 \%)$ were state police/highway patrols. In terms of size, ninety-one agencies served jurisdictions with fewer than 10,000 residents (10\%), 137 served jurisdictions with between 10,000 and 49,999 residents (16\%), 165 served jurisdictions with between 50,000 and 99,999 (19\%), and 439 agencies served jurisdictions with 100,000 or more residents (50\%); population estimates were missing for 39 agencies in the sample (5\%). One hundred and thirtyfive agencies were located in the Northeast (16\%), with 222 in the Midwest (26\%), 297 in the South (34\%), and 217 were located in the West (25\%) (see Alpert et al., 2013; Rojek, Alpert et al., $2012 \mathrm{~b}$ for a more detailed explanation of the data and sample). Agencies serve as the unit of analysis.

\section{Measures}

Dependent variable. The primary outcome of interest is whether an agency participated in a rigorous research partnership within the past five years, and it was constructed in two steps. First, the survey defined research partnership, broadly, as 'A relationship with a researcher with the goal to define or implement a research project. Examples include situations where police agencies and researchers work together to learn about training, leadership, policies, procedures, or other related matters. These efforts can also include police agencies and researchers working together to develop, implement, and/or monitor policies, new programs, and initiatives.' Two 
hundred and eighty departments (32\%) reported involvement and 68\% ( $n=591)$ reported no involvement in a research partnership within the last five years.

Agencies that had indicated participation in a research partnership (i.e., the abovementioned $n=280$ ) were then asked to define the nature of their partnership commitment in order to differentiate between both the formality and length of such partnerships. After all, not all partnerships are equipped to provide equal opportunity for research utilization/knowledge translation; the vast majority of prior research has not distinguished the nature of the police practitioner-researcher partnership (see Rojek, Smith et al., 2012a for an exception). Based on the three-category classification system outlined by the IACP (n.d. a, n.d. b; see also Rojek, Smith et al., 2012a), agency representatives were asked to choose among the following:

(1) cooperation - defined as short term and informal partnerships that may involve such efforts as the agency seeking advice from a researcher or simply providing the research partner data for analysis;

(2) coordination - defined as more formal partnerships that center on a specific project or goal, such as contracting a researcher to conduct a specific analysis or jointly securing grant funding with a researcher to evaluate a specific initiative; the partnership ends with the conclusion of the project; and

(3) collaboration - defined as formalized long-term partnerships where police agencies and researchers work together on multiple projects over time (e.g., could involve a MOU or contract between an agency and university or researcher for engaging in ongoing and multiple research efforts).

In recognition that some agencies may have participated in more than one research partnership over the past five years, the respondents could identify more than one type if they have been involved in different types of partnerships. Thus, agencies that had been involved in a cooperation type partnership and a coordination type were asked to check both the cooperation and coordination categories. One hundred and eighty-five (21\%) departments indicated they had engaged in a cooperation partnership, with fewer agencies reporting involvement in coordination $(n=160$; $18 \%)$ and collaboration $(n=83 ; 10 \%)$ partnerships, respectively.

However, the three-category classification system was designed to be ranked according to the level of sophistication and opportunity for knowledge translation/exchange between researchers and practitioners, with 'cooperation' being the lowest followed by 'coordination' and then 'collaboration'. As such, we were not particularly interested in examining 'cooperation' partnerships (e.g., short-term/informal, with an agency sometimes simply providing data to researchers). Instead, the focus of the current study was placed on the 'coordination' and 'collaboration' partnerships. Rigorous research partnership was measured using a dummy variable $(1=$ yes $)$ if an agency indicated that they had participated in either a coordination or collaboration partnership in the past five years. ${ }^{3}$ One hundred and eighty-two departments $(21 \%)$ - or approximately one-fifth of the sample - reported in the affirmative and 667 agencies (79\%) reported no such involvement in rigorous research partnerships.

Covariates (full sample). Given that the goal was to explore the influence of an agency's orientation to research on involvement in research partnerships, the survey asked respondents about two factors. For one, agencies were asked how often they use research to inform their decisions on policy development and operations. Uses research to inform decisions was measured at the ordinal level, with a response mode consisting of 0 ('never'), 1 ('seldom'), 2 ('sometimes'), and 3 ('very often'). The mean response was $1.95(S D=.82)$. Next, and building on the International Association of Chiefs of Police (2011) study discussed earlier, they survey asked about the source of research outlets. Using a series of dummy variables $(1=y e s)$, agencies were asked to indicate the whether or not they used academic journals, NIJ publications, and/or professional publications (e.g., Police Chief Magazine, FBI Law Enforcement Bulletin). Thirty- 
three percent of the sample reported using academic journals $(n=278), 55 \%$ used NIJ publications $(n=469)$, and $82 \%$ reported using professional publications $(n=692)$.

Dummy variables $(1=$ yes $)$ were used to measure the region of the country where the agency was located. They were broken down into the northeast $(n=130 ; 15 \%)$, Midwest $(n=217 ; 26 \%)$, south $(n=291 ; 34 \%)$, and west $(n=211 ; 25 \%)$ regions; northeast was used as the reference category. Type of agency was also captured using a series of dummies: police department $(n=424$; $50 \%)$, county sheriff $(n=392 ; 46 \%)$, and state police/highway patrol $(n=33 ; 4 \%)$, with county sheriff as the reference group. Lastly, a dummy variable was created to account for the size of the agency; $1=$ agencies with $100+$ sworn officers $(n=427 ; 50 \%)$.

Additional covariates (larger models). Prior descriptive analyses (see Alpert et al., 2013; Rojek, Smith et al., 2012a) of the current sample have indicated that larger agencies are most likely to engage in partnerships in general and in 'coordination' and/or 'collaboration'-style partnerships more specifically although involvement is still far from universal. For this reason, an effort was made to take a deeper look into larger agencies with more than 100 sworn officers. Supplemental measures from the 2007 LEMAS survey were used to examine another set of organizational characteristics and their potential influence on the likelihood of forming a rigorous research partnership. LEMAS is administered by the Bureau of Justice Statistics every few years, and the 2007 iteration (like all previous versions) employs both a long form' format for all agencies with over 100 sworn officers and 'short form' format for smaller agencies that asks fewer questions (see Reaves, 2010). Therefore, the LEMAS sample of agencies with 100 or more sworn personnel was combined with the current sample of departments with 100+ sworn officers. Excluding state police/highway patrol, a total of 335 out of 397 local/municipal police departments and county sheriffs from the national survey were matched with organizational characteristics from the 2007 LEMAS survey.

In order to assess the impact of agency size, a series of six dummy variables $(1=$ yes $)$ were created: $100-199$ sworn $(n=114 ; 34 \%)$, which was used as the reference category; 200-299 sworn $(n=61 ; 18 \%) ; 300-399$ sworn $(n=45 ; 13 \%) ; 400-499$ sworn $(n=31 ; 9 \%) ; 500-999$ sworn $(n=35$; $10 \%) ; 1,000+$ sworn $(n=49 ; 15 \%)$. LEMAS also provided a number of questions, which were used to create three scales. A problem-solving scale was measured as an additive index that consists of four questions regarding whether or not an agency $(1=$ yes; $0=n o): 1)$ actively encourages patrol officers to engage in SARA-type problem-solving projects, 2) includes collaborative problemsolving projects in the evaluation criteria of patrol officers, 3) upgraded technology to support the analysis of community problems, and 4) conducted or sponsored a survey of citizens on crime, fear or crime, or satisfaction with police services. Ranging from 0 to 4 , the sample of agencies with $100+$ officers had a mean of $1.95(S D=1.34)$.

A partnership scale was created using another additive index to capture the degree to which agencies partner with organizations and entities other than researchers. LEMAS inquired about nine such organizations/entities, including advocacy groups, business groups, faith-based organizations, local government agencies (non-law enforcement), other law enforcement agencies, neighborhood associations, senior citizen groups, school groups, and youth service organizations. The scale ranged from 0 to 9 with a mean of $5.99(S D=3.11)$. A similar approach was taken with the computer analysis scale measured as an additive index of whether agencies used computers to accomplish: 1) analysis of community problems, 2) crime analysis, 3) crime mapping, 4) hotspot identification, and 5) intelligence gathering ( mean $=3.95 ; S D=1.42$; range $0-5$ ). Collectively, these three measures developed through the LEMAS data were intended to examine if the use of analytic approaches or openness to other partnerships predicts participating in partnerships with researchers. Summary statistics for each of the variables in both the full sample and sub-sample of larger agencies are presented in Table 1.

\section{Analytic strategy}

The analysis was carried out in two phases - one for the full sample and another for the subsample of larger agencies, specifically local/municipal police departments and county sheriffs, 
Table 1. Descriptive statistics.

\begin{tabular}{|c|c|c|}
\hline Variable & Mean (SD) & Range \\
\hline \multicolumn{3}{|l|}{ Dependent Variable } \\
\hline Rigorous Research Partnership & $.21(-)$ & $0-1$ \\
\hline \multicolumn{3}{|l|}{ Covariates (full models) } \\
\hline Uses Research to Inform Decisions & $1.95(.82)$ & $0-3$ \\
\hline Uses Academic Journals & $.33(-)$ & $0-1$ \\
\hline Uses NIJ Publications & $.55(-)$ & $0-1$ \\
\hline Uses Professional Publications & $.82(-)$ & $0-1$ \\
\hline Northeast & $.15(-)$ & $0-1$ \\
\hline Midwest & $.26(-)$ & $0-1$ \\
\hline South & $.34(-)$ & $0-1$ \\
\hline West & $.25(-)$ & $0-1$ \\
\hline Police Department & $.50(-)$ & $0-1$ \\
\hline County Sheriff's & $.46(-)$ & $0-1$ \\
\hline State Police/Highway Patrol & $.04(-)$ & $0-1$ \\
\hline 100+ Sworn Officers & $.50(-)$ & $0-1$ \\
\hline \multicolumn{3}{|l|}{ Covariates (larger models) } \\
\hline Uses Research to Inform Decisions & $2.16(.68)$ & $0-3$ \\
\hline Uses Academic Journals & $.45(-)$ & $0-1$ \\
\hline Uses NIJ Publications & $.67(-)$ & $0-1$ \\
\hline Uses Professional Publications & $.86(-)$ & $0-1$ \\
\hline Northeast & $.10(-)$ & $0-1$ \\
\hline Midwest & $.17(-)$ & $0-1$ \\
\hline South & $.47(-)$ & $0-1$ \\
\hline West & $.26(-)$ & $0-1$ \\
\hline Police Department & $.63(-)$ & $0-1$ \\
\hline 100-199 Sworn & $.34(-)$ & $0-1$ \\
\hline 200-299 Sworn & $.18(-)$ & $0-1$ \\
\hline 300-399 Sworn & $.13(-)$ & $0-1$ \\
\hline 400-499 Sworn & $.09(-)$ & $0-1$ \\
\hline 500-999 Sworn & $.10(-)$ & $0-1$ \\
\hline $1,000+$ Sworn & $.15(-)$ & $0-1$ \\
\hline Problem-Solving Scale & $1.95(1.34)$ & $0-4$ \\
\hline Partnership Scale & $5.99(3.11)$ & $0-9$ \\
\hline Computer Analysis Scale & $3.95(1.42)$ & $0-5$ \\
\hline
\end{tabular}

with more than 100 sworn officers. Given that the dependent variable was measured dichotomously $(0,1)$, the data were estimated using a series of logistic regressions. There was a minor issue with missing data (22 agencies), which was addressed using the listwise deletion of cases. This reduced the sample size for the full models from 871 to 849 . The sub-sample included 335 agencies.

\section{Results}

\section{Full model}

Table 2 provides the results from the logistic regression equations. Model 1 on the left-side column presents the findings from the full sample, predicting whether an agency reported engaging in either a coordination or collaboration partnership - representing the more formal relationships of interest as opposed to a cooperation partnership - in the past five years. The coefficients listed are odds ratios (OR), with values greater than one denoting a positive relationship between the covariate and the outcome whereas those values less than one indicate a negative relationship. The model fits the data well (Log-likelihood $=692.44 ; p<.01$ ), and it explains $31 \%$ of the variance in the dependent variable. Agencies use of research in general to inform decisions on policies and operations as well as the use of academic journals or NIJ publications increases the odds of partnership participation, respectively. In fact, the odds of partnership participation were more than three times greater for those departments who used NIJ publications compared to those who reported they do not $(\mathrm{OR}=3.67 ; p<.01)$, which suggests that agencies who look to NIJ 
Table 2. Full sample and larger agencies (100+ sworn).

\begin{tabular}{lcc}
\hline Variables & $\begin{array}{c}\text { Model } 1 \text { (Full) } \\
\text { Odds Ratio (SE) }\end{array}$ & $\begin{array}{c}\text { Model } 2 \text { (Sub-Sample) } \\
\text { Odds Ratio (SE) }\end{array}$ \\
\hline Uses Research to Inform Decisions & $1.47^{*}(.15)$ & $1.21(.23)$ \\
Uses Academic Journals & $1.74^{* *}(.21)$ & $1.58(.31)$ \\
Uses NIJ Publications & $3.67^{* *}(.25)$ & $5.47^{* *}(.41)$ \\
Uses Professional Publications & $.44^{* *}(.31)$ & $.35^{*}(.47)$ \\
Midwest & $1.16(.33)$ & $1.07(.59)$ \\
South & $.97(.31)$ & $.88(.53)$ \\
West & $1.25(.33)$ & $1.21(.55)$ \\
Police Department & $2.43^{* *}(.21)$ & $3.57^{* *}(.33)$ \\
State Police/Highway Patrol & $3.54^{* *}(.42)$ & - \\
100+ Sworn Officers & $4.23^{* *}(.23)$ & - \\
200-299 Sworn & - & $1.48(.42)$ \\
300-399 Sworn & - & $1.83(.47)$ \\
$400-499$ Sworn & - & $5.65^{* *}(.53)$ \\
500-999 Sworn & - & $4.82^{* *}(.48)$ \\
1,000+ Sworn & - & $11.39^{* *}(.49)$ \\
Problem-Solving Scale & - & $1.23(.12)$ \\
Partnership Scale & - & $1.04(.06)$ \\
Computer Analysis Scale & - & $.97(.13)$ \\
Log-likelihood & $692.44^{* *}$ & $317.63^{* *}$ \\
Pseduo-R & .31 & .42 \\
N & 849 & 335 \\
\hline
\end{tabular}

Note: Entries are odds ratios with standard errors in parentheses.

${ }^{*} p<.05 ;{ }^{* *} p<.01$ (two-tailed test).

publications to inform their decisions are much more likely to engage in partnerships. Interestingly, the reported use of professional publications (e.g., Police Chief Magazine, FBI Law Enforcement Bulletin) decreased the odds of engaging in a partnership by $56 \%$ $(\mathrm{OR}=.44 ; p<.01)$.

Using the northeast as the reference category, there were no significant differences in partnership participation across regions of the country (Midwest, South, and West). Compared to county sheriff's, both local police departments $(\mathrm{OR}=2.43 ; p<.01)$ and state police/highway patrols $(\mathrm{OR}=3.54 ; p<.01)$ were more likely to be involved in partnerships. As expected, agencies with over 100 sworn officers were more than four times as likely to have reported involvement in a partnership within the past five than smaller departments - further justifying a deeper examination of those larger agencies.

The specific research outlets where agencies seek out and receive information to make decisions on policies and operations warrant further discussion and examination. Agencies, for example, might rely on a combination of research outlets for information (i.e., interaction effects might be taking place). In other words, affirmative responses to the use of academic journals, NIJ publications, or professional publications are not mutually exclusive. Due to these scenarios, an additional set of dichotomous variables $(1=y e s)$ was created to more effectively tease out the aforementioned findings: no use of any publications, academic journals only, NIJ publications only, professional publications only, as well as a number of combinations (e.g., professional and NIJ publications; academic journals and NIJ publications).

These supplemental analyses were conducted to examine the interactions of the various research/publication outlets - comparing the use of professional publications to both NIJ publications and academic journals. The newly created dummy variables were then entered into the multivariate analysis from Table 2, with the use of professional publications only serving as the reference category. Table 3 presents the results from the new analysis. The other covariates hold their prior levels regarding statistical significance and direction of association, and, therefore, were not reported. Comparing professional publications to NIJ publications (as well as combination between the two): agencies reporting only the use of professional publications had the lowest participation rate at $8.1 \%$, followed by not using either outlet (11.3\%), then the use of NIJ and 
Table 3. Odds-ratios for interactions with professional publications and specific research-based outlets for all agencies.

\begin{tabular}{lccc}
\hline Interactions & \# of Agencies in Category & \% Reporting Partnership & Odds Ratio \\
\hline NIJ Publication-Professional Publication & & & \\
$\quad$ Professional Only & $(n=247)$ & $8.1 \%$ & Reference \\
No Professional or NIJ & $(n=118)$ & $11.3 \%$ & 2.12 \\
NIJ Only & $(n=24)$ & $41.7 \%$ & $8.82^{* *}$ \\
Professional and NIJ & $(n=445)$ & $30.8 \%$ & $4.19^{* *}$ \\
Academic Journals-Professional Publications & $(n=431)$ & $14.2 \%$ & Reference \\
$\quad$ Professional Only & $(n=141)$ & $14.2 \%$ & 1.52 \\
No Professional or Academic & $(n=16)$ & $31.3 \%$ & 1.81 \\
Academic Only & $(n=262)$ & $36.6 \%$ & $2.36^{* *}$ \\
Professional and Academic & & \\
\hline
\end{tabular}

${ }^{*} p<.05 ;{ }^{* *} p<.01$ (two-tailed test).

professional publications (30.8\%), and finally the use of only NIJ publications $(41.7 \%)$ - the highest participation rate, although only 24 agencies fell within this category. Although agencies reporting no use of NIJ or professional publications have greater odds of partnership participation relative to agencies reporting only the use of professional publications, the relationship is not statistically significant.

However, there is a significant relationship with agencies reporting only the use of NIJ publications, as well as NIJ and professional publications, relative to agencies reporting only the use of professional publications. Agencies reporting that they rely on NIJ publications are almost 9 times as likely to participate in a partnership $(\mathrm{OR}=8.82 ; p<.01)$ relative to agencies reporting professional publication use only, and agencies reporting the use of NIJ and professional publications have more than four times the likelihood of participation $(\mathrm{OR}=4.19 ; p<.01)$. The results suggest that agencies that look to NIJ publications to inform their decisions are more likely to engage in partnerships, whether they use NIJ publications alone or in conjunction with professional publications.

A similar approach was taken to compare professional publications to academic journals (as well as a combination between the two). The only statistically significant difference that emerged was between the reference category (professional publications only) and a combination of using professional publications with academic journals $(\mathrm{OR}=2.36 ; p<.01)$.

\section{Sub-sample (agencies with 100+ sworn officers)}

Model 2 on the right-side column of Table 2 shows the results from the sample of larger agencies with more than 100 sworn officers. One hundred and twenty-four agencies (37\%) in the subsample reported involvement in such a partnership, and 211 departments (63\%) indicated that they had not. Explaining more than $40 \%$ of the variance in the outcome of interest, it performed better than Model 1; however, it also included more variables. While the general use of research to inform decisions and the use of academic journals were no longer statistically significant, the pattern of significant relationships found for using NIJ publications and professional publications persisted. The odds of partnership participation were more than five times greater for those who used NIJ publications as opposed to those who reported they do not $(\mathrm{OR}=5.47 ; p<.01)$. Similar to the full sample model, the reported use of professional publications decreased the odds of partnership participation by $65 \%(\mathrm{OR}=.35 ; p<.05)$.

Again, there were no significant differences in partnership participation across the regions. Police departments were significantly more likely to participate in partnerships than sheriff's departments $(\mathrm{OR}=3.57 ; p<.01)$. Setting agencies with 100-199 sworn officers as the reference category, the other agency size ranges illustrate a positive relationship. While the increased odds for partnership participation were not significant for the first two categories (200-299 and 300-399 officers), agencies with 400-499 sworn personnel were just shy of being five times as 
likely and agencies with 1,000 plus sworn officers were more than eleven times as likely to report engagement in a rigorous partnership. All three scales derived from the 2007 LEMAS survey were not predictive of involvement in either a coordination or collaboration partnership over the last five years.

Similar to the approach taken with the full sample, we further explored the issue of specific research outlets. Results regarding only agencies with $100+$ sworn officers are presented in Table 4 . The supplemental analyses and presentation of findings are again similar to those for all responding agencies in Table 3. With agencies reporting only the use of professional publications set as the reference category, agencies who reported only using NIJ publications were thirteen times more likely to engage in partnerships $(\mathrm{OR}=13.29 ; p<.01)$. The odds were seven times greater $(\mathrm{OR}=7.03 ; p<.01)$ that an agency reporting the use of NIJ and professional publications engaged in a partnership relative to agencies who reported using only professional publications. The difference between the rates of partnership participation between agencies reporting the use of professional publications and neither outlet is also significant, where the odds are more than three times greater for agencies reporting neither $(\mathrm{OR}=3.32 ; p<.05)$, holding all other covariates constant.

A similar approach was taken to compare professional publications to academic journals (as well as a combination between the two) among the sample of agencies with 100+ sworn members. The only statistically significant difference that emerged was between the reference category (professional publications only) and a combination of using professional publications with academic journals $(\mathrm{OR}=2.40 ; p<.01)$.

\section{Discussion}

The current study focused on identifying factors that predict engagement in practitionerresearcher partnerships in U.S. law enforcement. To date, there have been no longitudinal examinations of the prevalence such partnerships. The field lacks studies/surveys using comparable samples over time for comparison. Still, it is reasonable to assume - with the increase in federal funding as well as advocacy from key organizations and police leaders - that law enforcement engages in more research partnerships and looks to the empirical and theoretical works of the research community to inform their decisions and agency operations today than was the case 30 or 40 years ago. While the current level of participation in partnerships falls well short of the International Association of Chiefs of Police (2004) goal of every agency in the United States being involved in one, it is within reason to conclude that partnerships have grown in number and accomplishment over the years. Forming partnerships in every agency may be unrealistic and unattainable for a variety of reasons, particularly because there are not enough researchers to support them.

Prior work has highlighted the limitations and shortcomings on the part of the research community to support the growth in partnerships with law enforcement, specifically as it relates to the relative

Table 4. Odds-ratios for interactions with professional publications and specific research-based outlets for large agencies (100+ sworn).

\begin{tabular}{|c|c|c|c|}
\hline Interactions & \# of Agencies in Category & $\%$ Reporting Partnership & Odds Ratio \\
\hline \multicolumn{4}{|c|}{ NIJ Publication-Professional Publication } \\
\hline Professional Only & $(n=76)$ & $10.5 \%$ & Reference \\
\hline No Professional or NIJ & $(n=36)$ & $30.6 \%$ & $3.32^{*}$ \\
\hline NIJ Only & $(n=11)$ & $45.5 \%$ & $13.29^{* *}$ \\
\hline Professional and NIJ & $(n=212)$ & $47.2 \%$ & $7.03^{* *}$ \\
\hline \multicolumn{4}{|c|}{ Academic Journals-Professional Publications } \\
\hline Professional Only & $(n=146)$ & $23.3 \%$ & Reference \\
\hline No Professional or Academic & $(n=40)$ & $32.5 \%$ & 1.74 \\
\hline Academic Only & $(n=7)$ & $42.9 \%$ & 1.60 \\
\hline Professional and Academic & $(n=142)$ & $52.1 \%$ & $2.40^{* *}$ \\
\hline
\end{tabular}

${ }^{*} p<.05 ;{ }^{* *} p<.01$ (two-tailed test). 
lack of reaching out to agencies and engaging in applied work. According to Rojek, Smith et al. (2012a), one of the primary reasons agencies have not participated in a partnership was due to the fact that they have not been approached by a researcher ( $27 \%$ of non-involvement). This suggests there has been a reluctance or lack of opportunity in both communities to interact and form personal relationships. As many police agencies and researchers who have collaborated with practitioners have noted, forming trust through personal links is a critical element for forming partnerships. In this way, the success of collaborations is similar to dating and every other type of relationship building and its subsequent maintenance.

The future expansion of police practitioner-researcher partnerships will also depend, at least in part, on the supply of researchers willing to engage in these efforts. From the researcher perspective, participation requires them to be pulled away from other research opportunities. For example, time spent trying to build relationships with police agencies or providing 'pro-bono' (i.e., non-funded) analyses/evaluation - with the hope that it translate into future opportunities and/or valuable department/officer data - means time not spent working on and attempting to produce research products (e.g., peer-reviewed academic articles). This is particularly relevant and challenging for untenured junior faculty members. It is unknown how many researchers desire to participate in partnerships with police practitioners, although it is reasonable to assume there are not enough willing researchers for every agency.

Relatedly, this research speaks to the broader issue of the effectiveness (or lack thereof) of researchers' ability to disseminate knowledge to police practitioners. It points to the specific outlets and mechanisms that connect with practitioners. Findings here do not reflect a strong connection of practitioners with the work of the research community (see also Rojek, Alpert et al., 2012 b) The most common response (82\%) provided by agency representatives when asked which research outlets they rely on to inform decisions were professional publications (e.g., Police Chief Magazine or FBI Law Enforcement Bulletin) - showcasing the importance of such outlets among practitioners. These are neither the outlets where members of the research community commonly publish their work, nor where academics are incentivized to publish. The overwhelming majority of academic researchers, who represent most of the police research community, publish their work almost exclusively in academic journals, which only $33 \%$ of agency respondents reported using as a research outlet. The findings of this research suggest that those practitioners who draw knowledge from research-based outlets - academic journals and NIJ publications - are more likely to engage in partnerships with researchers, presumably given their orientation toward research indicates a perceived value of working with researchers. Thus, if the goal is to increase these partnerships as advocated by NIJ, IACP and others, then a strategy to increase the number of police practitioners that look to these outlets for knowledge and ideas would be valuable.

Alternatively, researchers also need to improve the dissemination of their work to the practitioner community by publishing in professional publications. The two-communities perspective on research utilization (i.e., research translation) argues practitioners and researchers reflect separate cultures that 'often have conflicting values, different reward systems, and different languages' (Caplan, 1979, p. 459). Academic journals represent one of the clear manifestations of this gap. These articles are written for academic peers with jargon and concepts that may be unfamiliar to practitioners, and they focus on theoretical and empirical conclusions that may not be readily apparent to a practitioner as to how it applies to their work. Furthermore, access to peer-reviewed academic journals is restricted by pay walls/ firewalls, and a single article is costly (e.g., \$36 for 24-hour access to download one article from Police Quarterly). Even among those willing to seek out such journals, particularly mid-level managers (e.g., lieutenants) in research/planning units, these studies remain isolated in outlets reserved, almost exclusively, for people with a university affiliation and subscription. One potential recommendation to alleviate this problem is placing more onus and responsibility on the part of the editors of peerreviewed journals (particularly policing-related journals). Editors can accept program evaluations and policy-relevant papers with a stipulation that the author(s) at a minimum attempt to also disseminate the findings in professional publications. 
Writing to professional publications forces the researcher to write to the practitioner audience more directly. However, it is important to note there are additional barriers that academics must first consider while attempting to do so. Similar to peer-reviewed journals, there are a limited number of professional outlets that have national prominence and broad reach among practitioners. Next, professional outlets possess their own editors/editorial boards, whose publishing philosophies must cater to their specific audience(s). An academic's desire to write for practitioners - not to mention his/her ability to effectively condense the findings and message of the work into a piece that is brief and easily consumable - is likely insufficient. There may be limited space to publish content from researchers, and work deemed 'too negative or critical' of law enforcement runs the risk of being rejected.

Despite these concerns, funding agencies, such as NIJ or the COPS Office, can motivate researchers to engage in such efforts by stipulating publications in professional outlets as deliverable requirements. University faculty performance reviews that think more inclusively about research dissemination to include valuing publications in professional outlets would also provide support to these efforts. In connecting back to the present study, instead of waiting for more practitioners to start reading traditional research publications in the hope of expanding the pool of practitioners willing to partner with researchers, the latter should make more concerted efforts to expand this pool by directly disseminating their work in outlets that practitioners already value. If practitioners see researchers trying communicate their work in more familiar formats - professional publications - they may find more value the knowledge and skills that researchers can provide.

Although the degree of researcher-practitioner partnerships in American law enforcement has undoubtedly increased over the last few decades, the majority of police organizations have yet to foster meaningful relationships with members of the research community - as defined and measured by participation in a 'rigorous partnership.' We have characterized the level of collaboration between the two as 'present, but not prevalent' with much room for improvement. The current study uncovered more information about the organizational characteristics of police departments most open and willing to work with the research community. Because time and resources are limited, identification of such agencies should help motivated policing researchers more efficiently attempt to partner with those departments - reducing the level of risk involved in doing so. This study, in addition to prior work on the topic, also illustrates the shortcomings on the part of the research community to engage with policing practitioners and focus on applied work. Researchers, especially those in academia, must acknowledge and shoulder part of the blame for the lack of collaboration. It shows that the research/ academic community must change and adapt as well - on both the institutional and individual levels.

\section{Notes}

1. A review of the literature on organizational theories, particularly those related to law enforcement agencies (e.g., contingency theory, resources dependency theory, and institutional theory) was beyond the scope of this article. However, readers interested in more detail on the aforementioned organizational theories should consult King (2009) and Maguire (2014).

2. The review provided here only focuses on the history of police practitioner-researcher partnerships. For a more in-depth overview of the evolution of policing research - including the innovative efforts of August Vollmer, the 1967 President's Commission on Law Enforcement and Administration of Justice, the establishment of the National Institute of Justice, the growth in research on related topics that was spurred by funding from the Community Oriented Policing Services (COPS) Office - see Rojek et al. (2012b).

3. Therefore, the dummy variable 'rigorous research partnership' $(1=$ yes $)$ compares these agencies to all other departments that reported no partnerships and partnerships characterized as 'cooperation' or 'coordination'.

\section{Acknowledgments}

This research is supported by grant 2009-IJ-CX-0204 from the National Institute of Justice, the Office of Justice Programs, and the US Department of Justice. Points of view are those of the authors and do not necessarily represent the official position of the US Department of Justice. 


\section{Disclosure statement}

No potential conflict of interest was reported by the authors.

\section{Notes on contributors}

Jeff Rojek is the Director of the Center Anti-Counterfeiting and Product Protection at Michigan State University and an Associate Professor of Criminal Justice. His research largely focuses on police organizations, officer behavior, officer safety, and training. He is also a former police officer.

John A. Shjarback is an assistant professor in the Department of Law and Justice Studies at Rowan University. He earned his $\mathrm{PhD}$ in Criminology and Criminal Justice from Arizona State University. His research interests center on policing, specifically environmental and organizational influences on discretionary officer behavior, and current issues and trends.

John Andrew Hansen is an assistant professor in the Department of Criminology and Criminal Justice at Western Carolina University. He earned his $\mathrm{PhD}$ in Criminology and Criminal Justice from the University of South Carolina. His current research is focused on policing and conservation.

Geoffrey P. Alpert is a Professor of Criminology and Criminal Justice at the University of South Carolina and holds an appointment at Griffith University. He is also a Chief Research Advisor for the United States Department of Justice, National Institute of Justice. He has taught at the FBI National Academy, the Federal Law Enforcement Training Center and The Senior Management Institute for Police and is currently a Federal Monitor for the New Orleans Police Department and on the compliance team for the Portland, Oregon Police Bureau. He testified to the President's Task Force on $21^{\text {st }}$ Century Policing, and is a member of the International Association of Chiefs of Police Research Advisory Committee and Policy Center Advisory Group. For the past thirty years, his research interests have included police use of force, emergency driving and the linkages between researchers and practitioners.

\section{References}

Alpert, G. P., Rojek, J., \& Hansen, J. A. (2013). Building bridges between police researchers and practitioners: Agents of change in a complex world. Final Report to the National Institute of Justice. Washington, DC: Department of Justice.

Braga, A. D., \& Hinkle, M. (2010). The participation of academics in the criminal justice working group process. In J. M. Klofas, N. K. Hipple, \& E. F. McGarrell (Eds.), The new criminal justice: American communities and the changing world of crime control (pp. 114-120). New York, NY: Routledge.

Braga, A. D., Kennedy, D. M., Waring, E. J., \& Piehl, A. M. (2001). Problem-oriented policing, deterrence and youth violence: An evaluation of Boston's operation ceasefire. Journal of Research in Crime and Delinquency, 38 (3), 195-226.

Bratton, W. J. (2006). Research: a practitioner's perspective, from the streets. Western Criminology Review, 7, 1-6. Bueermann, J. (2012). Being smart on crime with evidence-based policing. NIJ Journal, 269, 12-15.

Caplan, N. (1979). The two-communities theory and knowledge utilization. American Behavioral Scientist, 22(3), $459-470$.

Green, L. W., Ottoson, J. M., Garcia, C., \& Haitt, R. A. (2009). Diffusion theory and knowledge dissemination, utilization, and integration in public health. Annual Review of Public Health, 30, 151-174.

Henry, A., \& MacKenzie, S. (2012). Brokering communities of practice: A model of knowledge exchange and academic-practitioner collaboration developed in the context of community policing. Police Practice and Research, 13(4), 315-328.

International Association of Chiefs of Police. (2004). Unresolved problems and powerful potentials: Improving partnerships between law enforcement leaders and university based researchers. Washington, DC: Author.

International Association of Chiefs of Police. (2011). Law enforcement research priorities for 2011 and beyond. Washington, DC: Author.

International Association of Chiefs of Police. (n.d. a). Establishing and sustaining law enforcement-researcher partnerships: Guide for researchers. Washington, DC: Author.

International Association of Chiefs of Police. (n.d. b). Establishing and sustaining law enforcement-researcher partnerships: Guide for law enforcement leaders. Washington, DC: Author.

King, W. R. (2009). Toward a life-course perspective of police organizations. Journal of Research in Crime and Delinquency, 46(2), 213-244.

Lang, E. S., Wyer, P. C., \& Eskin, B. (2007). Knowledge translation in emergency medicine: establishing a research agenda and guide map for evidence uptake. Academic Emergency Medicine, 14(11), 915-918. 
Lasker, R. D., Weiss, E. S., \& Miller, R. (2001). Partnership synergy: A practical framework for studying and strengthening the collaborative advantage. The Milbank Quarterly, 79(2), 179-205.

Maguire, E. R. (2014). Police organizations and the iron cage of rationality. In M. D. Reisig \& R. J. Kane (Eds.), The Oxford handbook of police and policing (pp. 68-98). New York: Oxford University Press.

McEwen, T. (2003). Evaluation of the locally initiated research partnership program. Washington, DC: National Institute of Justice.

McGarrell, E. F., Hipple, N. K., Corsaro, N., Bynum, T. S., Perez, H., Zimmerman, C., \& Garmo, M. (2009). Project Safe Neighborhood - A national program to reduce gun crime: Final project report. Washington, DC: National Institute of Justice.

National Institute of Justice. (2017). Policing: Strategic research plan, 2017-2022. Washington, DC: U.S. Department of Justice.

Reaves, B. A. (2010). Local police departments, 2007. Washington, DC: Bureau of Justice Statistics.

Roehl, J., Rosenbaum, D. P., Costello, S. K., Coldren, J. R., Schuck, A. M., Kunard, L., \& Forde, D. (2006). Strategic Approaches to Community Safety Initiative (SACSI) in 10 US cities: The building blocks for Project Safe Neighborhoods. Washington, DC: National Institute of Justice.

Rojek, J., Alpert, G., \& Smith, H. (2012b). The utilization of research by the police. Police Practice and Research, 13 (4), 329-341.

Rojek, J., Smith, H. P., \& Alpert, G. P. (2012a). The prevalence and characteristics of police practitioner-researcher partnerships. Police Quarterly, 15(3), 241-261.

Sherman, L. W. (2004). Research and policing: The infrastructure and political economy of federal funding. The ANNALS of the American Academy of Political and Social Science, 593(1), 156-178.

Stephens, D. W. (2010). Enhancing the impact of research on police practice. Police Practice and Research, 11, 150-154.

Vigoda, E. (2002). From responsiveness to collaboration: governance, citizens, and the next generation of public administration. Public Administration Review, 62(5), 527-540.

Wellford, C., Serpas, R., \& Firman, J. (2007). IACP launches new committee to guide law enforcement policy research. Police Chief Magaginze. Retrieved from http://www.policechiefmagazine.org/magazine/index.cfm? fuseaction=display_archandarticle_id=1294andissue_id=102007 